\title{
Role of nitric oxide in prevention diabetic nephropathy in females after menopause
}

\author{
Arwa Ahmed Abdel-Raheem ${ }^{1}$, Heba Ibrahim Hamed 2, El-Sayed Fahim ${ }^{1}$ and Ayman Saber Mohamed 1, * \\ ${ }^{1}$ Zoology Department - Faculty of Science - Cairo University - Egypt. \\ ${ }^{2}$ Biochemistry-National Institute of Diabetes and Endocrinology - Cairo University - Egypt.
}

GSC Biological and Pharmaceutical Sciences, 2022, 18(01), 138-145

Publication history: Received on 18 December 2021; revised on 20 January 2022; accepted on 22 January 2022

Article DOI: https://doi.org/10.30574/gscbps.2022.18.1.0034

\begin{abstract}
Background: Type 2 diabetes mellitus (T2DM) is a complex disease, which affects many organs besides the pancreas such as the liver, brain, eye, stomach, and kidney.

Purpose: The current study aimed to evaluate role of nitric oxide in prevention diabetic nephropathy in females after menopause.

Methods: Our study was carried out on 90 females and 90 males with T2DM aged over 45 years, randomly selected from the outpatient clinic of the National Institute for Diabetes and Endocrinology (NIDE). T2DM patients were divided into 3 subgroups; subgroup 1: patients without any complications, subgroup 2: patients with nephropathy complications (DN), and subgroup 3: patients with cardiovascular compactions (CVD).

Results: Result showed that dyslipidemia and oxidative stress was more pronounced in females rather than in male. While, kidney function markers was worse in male than female.

Conclusion: The current study shows that diabetic females are more susceptible to cardiovascular disease than males due to the depletion of estrogen in postmenopausal women, causing oxidative stress. On the other hand, diabetic males are more susceptible to diabetic nephropathy than females due to a decrease in nitric oxide level, which is considered a kidney protective factor.
\end{abstract}

Keywords: Diabetes mellitus; Oxidative stress; Cardiovascular diseases; Diabetic nephropathy; Gender effect

\section{Introduction}

Diabetes mellitus (DM) is a group of metabolic disorders characterized by progressive loss or dysfunction of pancreatic insulin-producing $\beta$-cells, resulting in multiple long-term complications and organ damage [1]. The disorder is predicted to 578 million in 2030 and inflated to 700 million by the year 2045 [2]. $75 \%$ of diabetic patients have type 2 DM. [3,1] Type 2 DM involves insulin resistance and/or decreased secretion of insulin [4].

Globally, around $18.8 \%$ of type 2 diabetes mellitus patients develop microvascular complications [5], and this proportion was increased to $45 \%$ in Middle East [6] and 47.8\% in African diabetes [3].

Diabetic complications include macrovascular (coronary heart disease, peripheral vascular disease, and stroke), microvascular (neuropathy, retinopathy, and nephropathy), and both macro and microvascular (diabetic foot) [7]. It is becoming clear that the main mechanism for cellular damage of T1DM, and T2DM diabetic complications is oxidative

\footnotetext{
${ }^{*}$ Corresponding author: Ayman Saber Mohamed

Zoology Department - Faculty of Science - Cairo University.
}

Copyright ( 2022 Author(s) retain the copyright of this article. This article is published under the terms of the Creative Commons Attribution Liscense 4.0 
stress and inflammation [8]. Oxidative stress causes a complex dysregulation of cell metabolism and cell-cell homeostasis; oxidative stress is particularly important in the pathogenesis of insulin resistance and $\beta$-cell dysfunction. [9] Diabetic nephropathy (DN) is one of the most frequent and dangerous complications of DM2, affecting about onethird of the patients with type 2 DM. [1] DN represents the major cause of end-stage renal failure [10]. Clinically, it is characterized by the development of proteinuria with a subsequent decline in glomerular filtration rate, which progresses over a long period, often over 10-20 years [11]. The main risk factor for diabetic nephropathy is hyperglycemia which induces the formation of advanced glycation end products that promote the production of ROS [12]. Oxidative stress is associated with metabolic changes and alterations in renal hemodynamics, which have synergistic effects in the development of DN [13].

Cardiovascular disorders (CVD) accounts for more than $80 \%$ of the mortality seen in the diabetic population, combining diabetes and heart disease equates to an approximately three-fold increased risk of myocardial infarction compared with the general population [14]. The main contributing factor for the increasing prevalence of CVD deaths is the increase in the cases of diabetes at very alarming rate, in particular, due to increasing prevalence of obesity, lifestyle choices, urbanization, aging, and genetic factors [1]. CVD in diabetes includes premature atherosclerosis, manifesting myocardial infarction and stroke are both examples of decreased heart function, with diastolic dysfunction being the more common [15].The current study aimed to use oxidative stress markers as early predictors of diabetes complications in type 2 diabetic patients.

\section{Research Design and Methods}

\subsection{Chemicals and reagents}

Biochemical kits were purchased from Al Kasr Al Ayeni and BIODIAGNOSTIC Company (El Moror St, Dokki, and EGY). HO-1 kit was purchased from Sigma-Aldrich (St. Louis, MO, USA).

\subsection{Ethical Consideration}

Experimental protocols and procedures used in this study were approved by the National Institute for Diabetes and Endocrinology (NIDE) with Ethical approval No. IDE00242 on 29/8/2018.

\subsection{Experimental design}

Our study was carried out on 30 females and 30 male's patients with T2DM aged from 38 to 59 years according to inclusion and exclusion criteria selected from the outpatient clinic of the NIDE. T2DM patients were divided into 3 subgroups; subgroup 1: patients without any complications, subgroup 2: patients with nephropathy complications (DN), and subgroup 3: patients with cardiovascular compactions (CVD). 10males and 10 females healthy subjects were taken as controls.

\subsection{Inclusion criteria}

Type 2 diabetes mellitus and age more than 45 years.

\subsection{Exclusion criteria}

Type 1 diabetes, other immune disorders, other endocrine disorders, smoking, and use of anti-inflammatory drugs.

\subsection{Demographic characteristics}

Included determination of age, sex, duration of diabetes, blood pressure and body mass index.

\subsection{Urine collection and Laboratory analysis}

Freshly voided random urine samples were obtained and stored at 4oC. All urine samples were analyzed within 6 hours of collection. Urine Microalbumin was quantitatively measured according to recommendations of Cambiaso et al. [16] Using immunoturbidimetry. The urinary creatinine level was analyzed according to the method of Tietz [17].

\subsection{Blood collection and laboratory analysis}

Blood was collected by venipuncture after a $8 \mathrm{hr}$ fast into a vacutainer with EDTA, Sodium Florid and Plain tubes. The collected blood (of Florid and Plain tubes) was separated by centrifugation (3000 rpm, $15 \mathrm{~min}$ ) to obtain plasma and serum which was stored at $-80{ }^{\circ} \mathrm{C}$ for the biochemical measurements. 
The fasting blood glucose (FBG) was estimated by the method of Freund et al [18], glycated hemoglobin , (HbA1c) [19], glucose-6-phosphate dehydrogenase [20], lactate [21], arginase [22], Heme Oxygenase-1 (HO-1) [23], hemoglobin (Hb) [24], bilirubin [25], triglycerides (TG) [26], total cholesterol (TC) [27], low density lipoprotein (LDL-C) [28], high density lipoprotein (HDL-C) [29], urea [30], malondialdehyde (MDA) [31], glutathione reduced (GSH) [32], catalase (CAT) [33], nitric oxide (NO) [34] were determined in the blood according to the manufacturer's instructions using Biodiagnostic kits (Giza, Egypt) , Sigma, using automated device Mindray, Hipro and LABOMED,INC UV-Vis spectrophotometer.).

Glomerular Filtration Rate (GRF) was calculated according to the equation of Levey, et al [35]:

$$
G R F=175 x\left(S_{C r}\right)^{-1.154} x(\text { age })^{-0.203} \times 1.212 \text { [if black] } x 0.742 \text { [if female] }
$$

Where GFR is expressed as $\mathrm{mL} / \mathrm{min} / 1.73 \mathrm{~m}^{2}$ of body surface area and serum creatinine $\left(\boldsymbol{S}_{\boldsymbol{C r}}\right)$ is expressed in mg/dL.

\subsection{Statistical analysis}

Values were expressed as mean SE. The comparisons within groups were evaluated utilizing two-way analysis of variance (ANOVA). The Tuckey test was used to compare the group means, and p 0.05 was considered statistically significant. SPSS, for Windows (version 20) was used for the statistical analysis.

\section{Results}

\subsection{Diabetic markers and hemoglobin}

A significant increase was noticed in fasting blood glucose (FBS) and glycated hemoglobin (HbA1C), while hemoglobin (Hb) decreased significantly in DM as compared to the control group (Table 1). Regarding sex, males showed a significant increase in FBS and Hb, compared to females in DN and CVD groups.

Table 1 Diabetic markers, $\mathrm{Hb}$ and bilirubin between males and females of control and diabetic groups

\begin{tabular}{|l|l|c|l|c|c|}
\hline \multirow{2}{*}{ Parameters } & Gender & \multicolumn{4}{|c|}{ Groups } \\
\cline { 2 - 6 } & Control & DM & DM+DN & DM+CVD \\
\hline \multirow{2}{*}{$\begin{array}{l}\text { FBS } \\
(\mathrm{mg} / \mathrm{dL})\end{array}$} & Fale & $74.00 \pm 2.8$ & $164.50 \pm 1.52^{\#}$ & $225.66 \pm 1.96^{\#}$ & $277.83 \pm 4.17^{\#}$ \\
\cline { 2 - 6 } & Female & $71.50 \pm 2.74$ & $144.83 \pm 6.61^{\#}$ & $184.83 \pm 1.93^{\# *}$ & $207.5 \pm 1.38^{\# *}$ \\
\hline $\begin{array}{l}\mathrm{HbA} 1 \mathrm{C} \\
(\%)\end{array}$ & Male & $4.89 \pm 0.04$ & $8.03 \pm 0.26^{\#}$ & $9.67 \pm 0.18^{\#}$ & $10.14 \pm 0.31^{\#}$ \\
\cline { 2 - 6 } & Female & $4.62 \pm 0.15$ & $8.36 \pm 0.12^{\#}$ & $9.43 \pm 0.20^{\#}$ & $11.21 \pm 0.49^{\#}$ \\
\hline $\begin{array}{l}\text { Arginase } \\
(\mathrm{U} / \mathrm{L})\end{array}$ & Male & $89.40 \pm 0.91$ & $90.67 \pm 0.55$ & $98.53 \pm 1.64$ & $110.75 \pm 0.74$ \\
\hline \multirow{2}{*}{$\begin{array}{l}\mathrm{Hb} \\
(\mathrm{g} / \mathrm{dL})\end{array}$} & Female & $92.27 \pm 1.82^{*}$ & $94.89 \pm 0.94$ & $101.82 \pm 6.24$ & $109.02 \pm 1.96$ \\
\cline { 2 - 6 } & Male & $15.48 \pm 0.39$ & $14.40 \pm 0.20^{\#}$ & $12.85 \pm 0.25^{\#}$ & $14.28 \pm 0.24^{\#}$ \\
\hline
\end{tabular}

\#: indicate significant $(\mathrm{P}<0.05)$ different compare to control; *: indicate significant $(\mathrm{P}<0.05)$ between males and females for each parameter.

\subsection{Lipid profile markers}

Table 2 Lipid profile markers between males and females of control and diabetic groups

\begin{tabular}{|l|l|l|c|c|c|}
\hline \multirow{2}{*}{ Parameters } & \multirow{2}{*}{ Gender } & \multicolumn{4}{|c|}{ Groups } \\
\cline { 2 - 6 } & & Control & DM & DM+DN & DM+CVD \\
\hline \multirow{2}{*}{$\begin{array}{l}\text { Cholesterol } \\
(\mathrm{mg} / \mathrm{dL})\end{array}$} & Male & $159.00 \pm 12.38$ & $192.83 \pm 10.49^{\#}$ & $207.33 \pm 14.55^{\#}$ & $228.83 \pm 15.70^{\#}$ \\
\cline { 2 - 6 } & Female & $168.50 \pm 13.57$ & $226.16 \pm 14.81^{\# *}$ & $233.00 \pm 11.6^{\# *}$ & $269.66 \pm 11.20^{\# *}$ \\
\hline \multirow{2}{*}{$\begin{array}{l}\text { Triglycerides } \\
(\mathrm{mg} / \mathrm{dL})\end{array}$} & Male & $68.83 \pm 7.92$ & $99.50 \pm 12.38^{\#}$ & $121.16 \pm 13.85^{\#}$ & $200.66 \pm 14.70^{\#}$ \\
\cline { 2 - 6 } & Female & $77.16 \pm 8.93$ & $107.33 \pm 9.17^{\# *}$ & $142.83 \pm 11.72^{\# *}$ & $229.50 \pm 14.72^{\# *}$ \\
\hline \multirow{2}{*}{$\begin{array}{l}\text { HDL } \\
(\mathrm{mg} / \mathrm{dL})\end{array}$} & Male & $68.50 \pm 1.14$ & $55.33 \pm 2.37^{\#}$ & $42.83 \pm 0.87^{\#}$ & $39.16 \pm 0.83^{\#}$ \\
\hline \multirow{2}{*}{ LDL } & Female & $65.50 \pm 1.83$ & $48.83 \pm 0.79^{\# *}$ & $45.16 \pm 1.01^{\# *}$ & $34.83 \pm 1.16^{\# *}$ \\
\hline
\end{tabular}




\section{\begin{tabular}{|l|l|l|l|l|l|}
\hline$(\mathrm{mg} / \mathrm{dL})$ & Female & $93.50 \pm 3.06$ & $144.83 \pm 1.22^{\# *}$ & $149.16 \pm 0.94^{\# *}$ & $168.66 \pm 2.12^{\# *}$ \\
\hline
\end{tabular} \#: indicate significant $(\mathrm{P}<0.05)$ different compare to control; *: indicate significant $(\mathrm{P}<0.05)$ between males and females for each parameter.}

As recorded in table 2 levels of cholesterol, triglycerides (TG), and low-density lipoprotein (LDL-C) increased significantly $(\mathrm{p}<0.05)$ while, high-density lipoprotein (HDL-C) decreased in the DM group as compared to the control grou The females showed significant increase $(\mathrm{p}<0.05)$ in cholesterol, triglycerides, and LDL-C and significant decrease in HDL-C compared to males.

\subsection{Kidney function markers}

Diabetic groups showed significant increase $(\mathrm{p}<0.05)$ in urea, creatinine, albumin/ creatinine $(A / C)$ ratio, SBP, NO while Glomerular Filtration Rate (GRF) decreased as compared to the control group (Table 3). Concerning to sex; males showed significant increase $(\mathrm{p}<0.05)$ in urea, creatinine, albumin/ creatinine $(\mathrm{A} / \mathrm{C})$ ratio, SBP while GRF and NO decreased significantly compared to females.

Table 3 Kidney function markers between males and females of control and diabetic groups

\begin{tabular}{|c|c|c|c|c|c|}
\hline \multirow[b]{2}{*}{ Parameters } & \multirow[b]{2}{*}{ Gender } & \multicolumn{4}{|c|}{ Groups } \\
\hline & & Control & DM & DM+DN & DM+CVD \\
\hline \multirow{2}{*}{$\begin{array}{l}\text { Urea } \\
(\mathrm{mg} / \mathrm{dL})\end{array}$} & Male & $25.66 \pm 1.90$ & $30.33 \pm 1.25$ & $49.16 \pm 3.19^{\#}$ & $39.66 \pm 1.28^{\#}$ \\
\hline & Female & $19.16 \pm 1.01$ & $23.1 \pm 1.19$ & $41.00 \pm 1.17^{\# *}$ & $35.50 \pm 1.05^{\# *}$ \\
\hline \multirow{2}{*}{$\begin{array}{l}\text { Creatinine } \\
(\mathrm{mg} / \mathrm{dL})\end{array}$} & Male & $0.86 \pm 0.02$ & $0.89 \pm 0.03$ & $1.32 \pm 0.02^{\#}$ & $0.96 \pm 0.01^{\#}$ \\
\hline & Female & $0.80 \pm 0.03$ & $0.82 \pm 0.02$ & $1.18 \pm 0.02^{\# *}$ & $0.90 \pm 0.013^{\# *}$ \\
\hline \multirow{2}{*}{$\begin{array}{l}\text { A/C Ratio } \\
(\mathrm{mg} / \mathrm{g})\end{array}$} & Male & $20.37 \pm 0.96$ & $27.30 \pm 1.06$ & $157.45 \pm 9.95^{\#}$ & $56.63 \pm 2.13^{\#}$ \\
\hline & Female & $22.36 \pm 0.96$ & $27.01 \pm 3.74$ & $115.75 \pm 3.14^{\# *}$ & $44.61 \pm 1.74^{\# *}$ \\
\hline \multirow{2}{*}{$\begin{array}{l}\text { GFR } \\
\left(\mathrm{ml} / \mathrm{min} / 1.73 \mathrm{~m}^{2}\right)\end{array}$} & Male & $111.26 \pm 1.17$ & $94.88 \pm 1.11$ & $72.50 \pm 1.24^{\#}$ & $86.16 \pm 1.11^{\#}$ \\
\hline & Female & $117.31 \pm 11.76$ & $94.75 \pm 1.50$ & $60.00 \pm 1.28^{\# *}$ & $78.85 \pm 1.53^{\# *}$ \\
\hline \multirow{2}{*}{$\begin{array}{l}\text { SBP } \\
(\mathrm{mmHg})\end{array}$} & Male & $118.33 \pm 2.10$ & $130.00 \pm 3.65^{\#}$ & $139.6 \pm 1.05^{\#}$ & $156.66 \pm 1.05^{\#}$ \\
\hline & Female & $113.33 \pm 2.10$ & $125.00 \pm 2.23^{\#}$ & $136.66 \pm 1.66^{\#}$ & $145.00 \pm 2.23^{\# *}$ \\
\hline \multirow{2}{*}{$\begin{array}{l}\text { DBP } \\
(\mathrm{mmHg})\end{array}$} & Male & $80.00 \pm 2.88$ & $85.00 \pm 2.23$ & $88.33 \pm 1.66^{\#}$ & $93.33 \pm 2.10^{\#}$ \\
\hline & Female & $75.00 \pm 2.23$ & $80.00 \pm 2.58$ & $83.33 \pm 2.10^{\#}$ & $88.33 \pm 1.66^{\#}$ \\
\hline \multirow{2}{*}{$\begin{array}{l}\text { NO } \\
(\mu \mathrm{M} / \mathrm{mL})\end{array}$} & Male & $262.81 \pm 2.17$ & $300.52 \pm 3.17 \#$ & $333.42 \pm 1.27 \#$ & $377.19 \pm 15.49 \#$ \\
\hline & Female & $261.22 \pm 1.51$ & $399.73 \pm 2.44^{\# *}$ & $406.05 \pm 3.71^{\# *}$ & $434.84 \pm 0.97^{\# *}$ \\
\hline
\end{tabular}

\#: indicate significant $(\mathrm{P}<0.05)$ different compare to control; *: indicate significant $(\mathrm{P}<0.05)$ between males and females for each parameter.

\subsection{Oxidative stress markers}

Table 4 Oxidative stress markers between males and females of control and diabetic groups

\begin{tabular}{|c|c|c|c|c|c|}
\hline \multirow[b]{2}{*}{ Parameters } & \multirow[b]{2}{*}{ Gender } & \multicolumn{4}{|l|}{ Groups } \\
\hline & & Control & DM & DM+DN & DM+CVD \\
\hline \multirow{2}{*}{$\begin{array}{l}\text { MDA } \\
\text { (nmoles/ml) }\end{array}$} & Male & $11.11 \pm 0.20$ & $13.34 \pm 0.28^{\#}$ & $16.44 \pm 0.18^{\#}$ & $19.42 \pm 0.34^{\#}$ \\
\hline & Female & $13.22 \pm 0.37$ & $15.60 \pm 0.17^{\# *}$ & $20.42 \pm 0.22^{\# *}$ & $24.02 \pm 0.55^{\# *}$ \\
\hline \multirow{2}{*}{$\begin{array}{l}\text { GSH } \\
\text { (nmoles/ml) }\end{array}$} & Male & $458.83 \pm 2.67$ & $445.82 \pm 1.73^{\#}$ & $432.59 \pm 1.00^{\#}$ & $425.19 \pm 1.56^{\#}$ \\
\hline & Female & $440.05 \pm 11.25$ & $431.49 \pm 10.50^{\# *}$ & $416.49 \pm 12.65^{\# *}$ & $407.88 \pm 10.72^{\# *}$ \\
\hline \multirow{2}{*}{$\begin{array}{l}\text { CAT } \\
(\mathrm{U} / \mathrm{mL} / \mathrm{min})\end{array}$} & Male & $1696.07 \pm 15.56$ & $1619.26 \pm 9.74 \#$ & $1563.07 \pm 13.17^{\#}$ & $1516.37 \pm 11.73^{\#}$ \\
\hline & Female & $1636.16 \pm 9.79$ & $1526.16 \pm 11.29$ \#* & $1436.16 \pm 8.39 \# *$ & $1304.50 \pm 6.58^{\# *}$ \\
\hline \multirow{2}{*}{$\begin{array}{l}\text { HO-1(ng bilirubin/mg } \\
\text { protein/hr) }\end{array}$} & Male & $49.35 \pm 1.59$ & $59.28 \pm 0.73^{\#}$ & $66.45 \pm 0.91^{\#}$ & $72.13 \pm 1.25^{\#}$ \\
\hline & Female & $54.28 \pm 0.87$ & $66.80 \pm 1.64 \# *$ & $73.50 \pm 0.57^{\# *}$ & $82.23 \pm 0.97$ \#* \\
\hline
\end{tabular}




\begin{tabular}{|l|l|c|c|c|c|}
\hline \multirow{2}{*}{$\begin{array}{l}\text { G6PD/Lactate } \\
\text { (U/g ) }\end{array}$} & Male & $170.95 \pm 17.35$ & $120.35 \pm 5.14^{\#}$ & $90.28 \pm 1.57^{\#}$ & $60.16 \pm 7.54^{\#}$ \\
\cline { 2 - 6 } & Female & $110.29 \pm 3.40$ & $70.51 \pm 4.23^{\# *}$ & $50.93 \pm 2.95^{\# *}$ & $40.47 \pm 3.47^{\# *}$ \\
\hline
\end{tabular}

\#: indicate significant $(\mathrm{P}<0.05)$ different compare to control; *: indicate significant $(\mathrm{P}<0.05)$ between males and females for each parameter.

Significant increase in the levels of heme-oxygenase-1 (HO-1), malondialdehyde (MDA) was noticed while G6PD/Lactate, glutathione reduced (GSH), and catalase (CAT) decreased in the DM group as compared to the control group (Table 4). The females showed significant increase in H0-1 and MDA levels while G6PD/Lactate, GSH, and CAT decreased as compared to males.

\section{Discussion}

Type 2 Diabetes Mellitus (T2DM) is a metabolic condition that affects more than 400 million individuals' worldwide, posing serious health and economic risks [36]. It is linked to insulin resistance [37].

Fasting glucose levels in diabetes patients were found to be high in this investigation. Diabetes is a metabolic condition defined by hyperglycemia caused by insulin secretion, insulin action, or a combination of the two. Male patients had poorer glycemic control than female ones. Women with normal glucose tolerance have been reported to be more insulin-sensitive and have better -cell activity when compared to men [38]. In addition, the role of testosterone shortage in the development of visceral adiposity, insulin resistance, and metabolic syndrome in older men has been extensively documented [38].

Hemoglobin levels in diabetes groups decreased as compared to control groups, according to our findings. Sustained hyperglycemia has a profound impact on RBCS shape and function, resulting in early ageing of circulating RBCs and a shorter lifespan [39]. In addition, impairment in erythropoietin (EPO) secretion within diabetic nephropathy patients leading to dysregulates red blood cell formation [40]. Regarding to gender, the female has lower mean levels than male. It's most likely a direct influence of sex hormones on erythropoiesis [41].

In the current study, dyslipidemia was established within diabetic patients by the increase in cholesterol, triglycerides, and LDL and Decrease HDL. Dyslipidemia is commonly associated with obesity and T2DM. Obesity may trigger changes to the body's metabolism that cause adipose tissue to release increased amounts of fatty acids, glycerol, hormones, proinflammatory cytokines, and other factors that are involved in the development of insulin resistance [42]. In the present study, dyslipidemia appears clearly in females rather than males. Menopausal status and the use of hormone therapy are two more factors that influence dyslipidemia risk in women [43].

In the current study, we found that blood pressure increased in diabetic patient. The hypertension increased in diabetic patients due to excess sodium retention, sympathetic nervous system activity, and activation of the renin-angiotensinaldosterone system, impaired endothelial cells and oxidative stress $[44,45]$. In this study, the increase in blood pressure was more pronounced in male patients. Androgens are known to raise blood pressure by activating the reninangiotensin system (RAS), which results in the generation of vasoconstrictor chemicals and a decrease in nitric oxide availability [46]. In addition, men's prorenin and renin levels, as well as plasma renin activity, were shown to be higher than women's [47].

In the present study increase levels of urea, create, microalbuminuria, nitric oxide, and decrease of GFR level in diabetic groups compared to control grou Hyperinsulinemia, which is inevitably associated to systemic insulin resistance in nondiabetic states, also plays a role by causing glomerular hyperfiltration, endothelial dysfunction and increased vascular permeability, all converging to albuminuria [48]. Our results show significant difference between male and female groups.

Despite estrogen insufficiency after menopause, female kidneys appear to be more protected than male kidneys, according to our findings. Renal protection may be due to an increase in NO levels in females. NO has a critical role in tubular transport autoregulation and modulation in the kidney [49]. It has been discovered that as chronic kidney disease (CKD) progresses, the overall generation of nitric oxide (NO) decreases [50]. It was reported that total NO production in the old male rat decreases dramatically as kidney disease progresses [51].

Furthermore, as men become older, their renal vasculature becomes increasingly reliant on nitric oxide. Endothelial dysfunction may be caused by testosterone deprivation, which reduces NO levels through controlling the expression and activity of NO synthase and raising ADMA expression [52]. 
In the current study, diabetic groups had higher levels of heme oxygenase (HO-1) and malondialdehyde (MDA), whereas G6PD/Lactate, glutathione reduced (GSH), and catalase (CAT) levels, indicating the presence of oxidative stress in diabetic patients.. Reactive oxygen species produced by glucose oxidation and protein glycation cause enzyme dysfunction, cellular machinery damage, and increased insulin resistance [53].

The novel ratio of G6PD/ lactate represents the glucose catabolism by HMP/glycolysis as an expression for using glucose to produce either antioxidants (GSH) or / energy. Due to the low amount of glucose that enters the cells in diabetic patients, the cells prefer to use most of the glucose to produce energy rather than antioxidants resulting in oxidative stress conditions as a biomarker for diabetic complications. In this study, females exhibited a higher oxidative state than males. There was a variation in circulatory estrogen levels in postmenopausal ladies Menopause poses a significant health risk to women since it is accompanied with a rise in systemic oxidative stress, which is produced by the loss of estrogen, an antioxidant [53]

\section{Conclusion}

According to the current study, diabetic female are more susceptible to cardiovascular disease than diabetic males due to estrogen loss in postmenopausal women, which causes oxidative stress. Diabetic males, on the other hand, are more susceptible to diabetic nephropathy than diabetic females, due to decrease in nitric oxide levels, a kidney protective factor.

\section{Compliance with ethical standards}

\section{Acknowledgments}

The authors extend their appreciation to the Faculty of Science, Cairo University for supporting the current work.

\section{Disclosure of conflict of interest}

The authors declare that there is no conflict of interest.

\section{References}

[1] Cirovic A, Vujacic M, Petrovic B, Cirovic A, Zivkovic V, Djonic D, et al. Vascular Complications in Individuals with Type 2 Diabetes Mellitus Additionally Increase the Risk of Femoral Neck Fractures Due to Deteriorated Trabecular Microarchitecture. Clacified Tissue International. 2021.

[2] Saeedi, Petersohn, Salpea P, Malanda. Global and regional diabetes prevalence estimates for 2019 and projections for 2030 and 2045: Results from the International Diabetes Federation Diabetes Atlas, 9th edition. Diabetes Research and Clinical Practice. 2019; 157.

[3] Seid MA, Akalu Y, Gela YY, Belsit Y, Diress M, Fekadue SA, et al. Microvascular complications and its predictors among type 2 diabetes mellitus patients at Dessie town hospitals, Ethiopia. Diabetology\&Metabolic Syndrom. 2021.

[4] Darenskaya MA, Kolesnikova LI, Kolesnikov SI. Oxidative Stress: Pathogenetic Role in Diabetes Mellitus and Its Complications and Therapeutic Approaches to Correction. Bulletin of Experimental Biology and Medicin. 2021; 179-189.

[5] Kosiborod M, Gomes MB, Nicolucci A. Vascular complications in patients with type 2 diabetes: prevalence and associated factors in 38 countries (the DISCOVER study program). Cardiovascular Diabetology. 2018; 17(1).

[6] Cheema S, Malsonneuve P, Zirie M. Risk Factors for Microvascular Complications of Diabetes in a High-Risk Middle East Population. National Center for Biotechnology Information. 2018; 1-8.

[7] Papatheodorou K, Banach M, Bekiari E, Rizzo M, Edmonds M. Complications of Diabetes 2017. Jorna of Diabetes research. 2018.

[8] Pickering PJ, Rosado CJ, Sharma A, Buksh S, Tate M, de Haan JB. Recent novel approaches to limit oxidative stress and inflammation in diabetic complications. Clinical \& Translational Immunology. 2018; 7(4): e1016.

[9] Chandirasegaran G, Elanchezhiyan C, Ghosh K, Manivel G, Hassan T. Diabetes Mellitus Induced Oxidative Stress, Inflammation and Apoptosis: A Concise Review. EC Diabetes and Metabolic Research. 2019; 3(1): 10-17. 
[10] Nazar CM. Diabetic nephropathy; principles of diagnosis and treatment of diabetic kidney disease. J Nephropharmacol. 2014; 3(1): 15-20.

[11] Asmat U, Abad K, Ismail K. Diabetes mellitus and oxidative stress-A concise review. Saudi Pham J. 2016; 24(5): 547-553.

[12] Ebaid H, Bashandy SAE, Abdel-Mageed AM, Al-Tamimi J, Hassan I, Alhazza IM. Folic acid and melatonin mitigate diabetic nephropathy in rats via inhibition of oxidative stress. Nutrition \& Metabolism. 2020; $17: 6$.

[13] Sifuentes-Franco S, Padilla-Tejeda D, Carrillo-Ibarra S, Miranda-Díaz AG. Oxidative stress, apoptosis, and mitochondrial function in diabetic nephropathy. Int. J. Endocrinol. 2018; 1875870.

[14] Abdul-Ghani M, DeFronzo RA, Del Prato S, Chilton R, Singh R, Ryder REJ. Cardiovascular Disease and Type 2 Diabetes: Has the Dawn of a New Era Arrived? Diabetes Care. 2017; 40(7): 813-820.

[15] Forbes JM, Cooper ME. Mechanisms of diabetic complications. Physiol Rev. 2013; 93: 137-188.

[16] Cambiaso CL, Collet-Cassart D, Lievens M. Immunoassay of low concentrations of albumin in urine by latex particle counting. Clin Chem. 1988; 34: 416-418.

[17] Schirmeister J. Determination of creatinine in serum. Dtsch Med Wschr. 1964; 89: 1940.

[18] Freund A, Johnson SB, Rosenbloom A, Alexander B, Hansen CA. Subjective symptoms, blood glucose estimation, and blood glucose concentrations in adolescents with diabetes. Diabetes Care. 1986; 9: 236-243.

[19] Gallop PM, Flückige R, Hanneken A, Mininsohn MM, Gabbay KH. Chemical quantitation of hemoglobin glycosylation: Fluorometric detection of formaldehyde released upon periodate oxidation of glycoglobin. Analytical Biochemistry. 1981; 117(2): 427-432.

[20] Kornberg A, Horecker BL. Glucose- 6- Phosphate Dehydrogenase. Methods Enzymol. 1955; 1: 323-329.

[21] Poso AR, Lampinen KJ, Rasanen LA. Distribution of lactate between red blood cells and plasma after exercise. Equine vet. J., Suppl. 1995; 18: 231-234.

[22] Marsch W. Determination of arginase activity. Clin. Chem. 1965; 11: 620-630.

[23] Basu M, Saha S, Ukil A. pectrophotometric Assessment of Heme Oxygenase-1 Activity in Leishmania-infected Macrophages. Bio-protocol. 2020; 10(7): e3578.

[24] Franco RS. Hemoglobin. In Kaplan A, editor. Clin Chem. The C.V. Mosby Co. St Louis: Princeton; 1984. 1294-1296\& 418.

[25] Walter M, Gerade H. Ultramicromethod for determination of conjugated and total bilirubin in serum or plasma. Microchem. J. 1970; 15: 231-238.

[26] Stein EA, Myers G. Lipids, lipoproteins and apolipoproteins.In: Burtis, C.A., Ashwood, E.R. (Eds.). In In Tietz Textbook of Clinical Chemistry.: WB Saunders Company; 1994. 1002-993.

[27] Richmond W. Preparation and properties of a cholesterol oxidase from Nocardia s and its application to the enzymatic assay of total cholesterol in serum. Clin. Chem. 1973; 19(12): 1350-1356.

[28] Wieland H, Seidel D. A simple specific method for precipitation of low density lipoproteins. J. Lipid Res. 1983; 24(7): 904-909.

[29] Lopes-Virella MF, Stone P, Ellis S, Colwell JA. Cholesterol determination in high-density lipoproteins separated by three different methods. Clin. Chem. 1977; 23: 882-884.

[30] Fawcett JK, Soctt JE. A RAPID AND PRECISE METHOD FOR THE DETERMINATION OF UREA. J Clin Pathol. 1960; 13: $156-159$.

[31] Ohkawa H, Ohishi N, Yagi K. Assay for lipid peroxides in animal tissues by thiobarbituric acid reaction. Anal.Biochem. 1979; 95: 351-358.

[32] Beutler E, Duron 0, Kelly MB. Improved method for the determination of blood glutathione. J. Lab. Clin. Med. 1963; 61: 882-888.

[33] Aebi H. Catalase in vitro. Methods enzymol. 1984; 105: 121-126.

[34] Montgomery HAC, Dymock JF. The determination of nitrite in water. Analyst. 1961; 86: 414-416. 
[35] Levey AS, Stevens LA, Schmid CH, Zhang YL, Castro AF. A new equation to estimate glomerular filtration rate. 3rd ed. Feldman HI, Kusek JW, Eggers P, Van Lente F, Greene T, Coresh J, editors.: Ann Intern Med. 2009.

[36] Cho NH, Shaw JE, Karuranga S, Huang Y, da Rocha Fernandes JD, Ohlrogge AW, et al. IDF Diabetes Atlas: Global estimates of diabetes prevalence for 2017 and projections for 2045. Diabetes Res Clin Pract. 2018; 138: 271-281.

[37] ADA. American Diabetes Association; Classification and diagnosis of diabetes: standards of medical care in diabetes. Diabetes Care. 2019; 42(5): 13-28.

[38] Willer K, Kosi L, Lin L, Mihaljevic R. Gender-based differences in glycaemic control and hypoglycaemia prevalence in patients with type 2 diabetes: results from patient-level pooled data of six randomized controlled trials A. Diabetes, Obesity and Metabolism. 2015; 17: 533-540.

[39] Rajab AM, Haider KH. Hyperglycemia and RBCs: too sweet to survive. International Journal of Diabetes in Developing Countries. 2018; 38: 357-365.

[40] Al-Adhar SI, Karem KK, Jassim WK. An Evaluation Of Hemoglobin Concentration in Patients With Diabetes Mellitus Type 2. International Journal of Drug Delivary Technology. 2019; 9(2): 177-181.

[41] Wiliam MG. The sex difference in haemoglobin levels in adults - mechanisms, causes, and consequences. ELSEVIER. 2014; 28(2): 41-7.

[42] Kahn SE, Hull RL. Utzschneider KM. Mechanisms linking obesity to insulin resistance and type 2 diabetes. Nature. 2006; 444(7121): 840-846.

[43] Sharma P, Nagy CD, Blumenthal RS. Dyslipidemia Management in Women and Men:Exploring Potential Gender Differences. In Legato M, editor. Principles of Gender-Specific Medicin (Second Edition).: Science direct. 2010. 175-185.

[44] Peter NVB, Robert T. Hypertension in Diabetic Nephropathy: Epidemiology, Mechanisms, and Management. Adv Chronic Kidney Dis. 2011; 18(1): 28-41.

[45] Carette C, Dubois-Lafogue D, Gautier JF, Timsit J. Diabetes mellitus and glucose-6-phosphate dehydrogenase deficiency: From one crisis to another. Diabetes\&Metabolism. 2011; 37(1): 79-82.

[46] Reckelhoff F. Gender Differences in the Regulation of Blood Pressure. Hypertension. 2001; 37: 1199-1208.

[47] Silbiger S, Neugarten J. Gender and Human Chronic Renal Disease. Gender Medicine. 2008; 5: S3-S10.

[48] Spoto B, Pisano A, Zoccali C. Insulin resistance in chronic kidney disease: a systematic review. American journal of physiology.Renal physiology. 2016; 311(6).

[49] Carlström M. Nitric oxide signalling in kidney regulation and cardiometabolic health. Nat Rev Nephrol. 2021; 17: 575-590.

[50] Baylis C. Nitric oxide deficiency in chronic kidney disease. Am J Physiol Renal Physiol. 2008; 294: F1-F9.

[51] Erdely A, Greenfeld Z, Wagner L, Baylis C. Sexual dimorphism in the aging kidney: Effects on injury and nitric oxide system. Kidney Int. 2003; 63: 1021-1026.

[52] Ahmed SB, Fisher NDL, Hollenberg NK. Gender and the Renal Nitric Oxide Synthase System in Healthy Humans. Clin J Am Soc Nephrol. 2007; 7: 916-931.

[53] Cervellati, Bergamini. Oxidative damage and the pathogenesis of menopause related disturbances and diseases. Clinical Chemistry and Laboratory Medicine (CCLM). 2015. 